https://doi.org/10.11646/zootaxa.4232.2.11

http://zoobank.org/urn:Isid:zoobank.org:pub:24B25647-2702-4829-9BC8-62CF53DEE4B9

\title{
Taxonomy of the Capensibufo rosei group (Anura: Bufonidae) from South Africa
}

\author{
A. CHANNING ${ }^{1}$, G.J. MEASEY ${ }^{2}$, A.L. DE VILLIERS ${ }^{3}$, A.A. TURNER ${ }^{3} \&$ K.A. TOLLEY ${ }^{4,5}$ \\ ${ }^{1}$ Unit for Environmental Sciences and Management, North-West University, Potchefstroom, 2520, South Africa \\ ${ }^{2}$ Centre for Invasion Biology, Department of Botany and Zoology, Stellenbosch University, Stellenbosch, South Africa \\ ${ }^{3}$ CapeNature, Private Bag X5014, Stellenbosch, 7599, South Africa \\ ${ }^{4}$ Department of Botany and Zoology, Stellenbosch University, Stellenbosch, South Africa \\ ${ }^{5}$ South African National Biodiversity Institute, Kirstenbosch Research Centre, Private Bag X7, Claremont 7735, South Africa
}

\begin{abstract}
A molecular and morphological study of the Mountain Toadlets, previously included in Capensibufo rosei, showed that there are several previously unrecognised species in this group. We describe three new species from the Hawekwas, Hottentots-Holland, Groenland and Riviersonderend Mountains; the DuToitskloof Mountains, and the Akkedis, Koeël and Kleinriviers Mountains, South Africa. Capensibufo rosei is restricted to the Table Mountain chain of the Cape Peninsula.
\end{abstract}

Key words: Capensibufo rosei, new species, South Africa

\section{Introduction}

Walter Rose collected a number of unusual small toads above Muizenberg, Cape Town, South Africa, in March 1925 (Rose 1926). These were described as Bufo rosei by Hewitt (1926a), who noted that the species lacked a tympanum. In the same issue of the Annals of the South African Museum, Hewitt (1926b) described Bufo tradouwi, remarking that it was similar to $B$. rosei, but that a distinct tympanum was present. Bufo tradouwi was then known from the Swellendam Mountains, Tradouws Pass, and George Mountain, while B. rosei was only known from the Cape Peninsula. Poynton (1964) believed that the visibility of the tympanum was variable, and so placed B. tradouwi as a junior synonym of B. rosei. As part of a study of African bufonids, Tandy \& Keith (1972) recognised both B. rosei and B. tradouwi. Grandison (1980) later erected the genus Capensibufo to accommodate these two species, based on anatomical differences including a reduction in cranial elements.

The status and relationships of these two species within the family Bufonidae remained in contention until Cunningham \& Cherry (2004) and Frost et al. (2006) confirmed the monophyly of the genus Capensibufo. The two species were each considered widespread until recently, when molecular analyses with greater geographic coverage confirmed that there are multiple distinct lineages within both species (Tolley et al. 2010). The C. rosei complex consists of at least four different clades, from separate mountain chains, that are distinct at the species level (Cressey et al. 2014). Mitochondrial sequence divergences between these clades (7-11\% for ND2; $2.5-4 \%$ for $16 \mathrm{~S}$ ) are at the lower range, although comparable with that found between other anuran species e.g. Hyperolius (Channing et al. 2013), Cacosternum (Conradie 2014), and Petropedetes (Loader et al. 2013) (now Arthroleptides Barej et al. 2014) further supporting the conclusion that these diverse mountains contain separate species (Tolley et al. 2010, Cressey et al. 2014).

At present, $C$. rose $i$ is listed as Vulnerable (VU) on the IUCN Red List given the continuing decline in the Area of Occupancy, quality of habitat, and the number of subpopulations (SA Frog \& IUCN-ASG 2010). However, the VU status is based on a distribution that includes all clades in C. rosei (i.e. sensu lato), covering an area of more than $6000 \mathrm{~km}^{2}$. The type locality for C. rosei, however, is "Muizenberg Mountain" on the Silvermine Plateau (above Muizenberg), which restricts C. rosei sensu stricto to the Cape Peninsula (Tolley et al. 2010, Cressey et al. 2014). Moreover, within the Cape Peninsula only two breeding populations are known, with several other breeding 
populations having disappeared since the 1980s (Cressey et al. 2014). Their disappearance is enigmatic, as several populations occurred within protected areas and there is no direct link with disease or anthropogenic causes such as habitat loss or fragmentation (Cressey et al. 2014). Tarrant et al. (2013) found no chytrid fungus in the Silvermine population of $C$. rosei. Nonetheless, the species cannot be re-assessed for extinction risk, until its taxonomic status is updated, making our taxonomic revision of these species essential for their conservation.

Overall, the presence of multiple distinct lineages with species-level sequence divergences in this genus indicates that a taxonomic revision is necessary, and this has been recognised for some time (Channing et al. 2011, Cressey et al. 2014). We examined fresh and museum material from across the range of $C$. rosei in order to revise the taxonomy to reflect the presence of distinct lineages. Here, we take the opportunity to describe three new species from the C. rosei group.

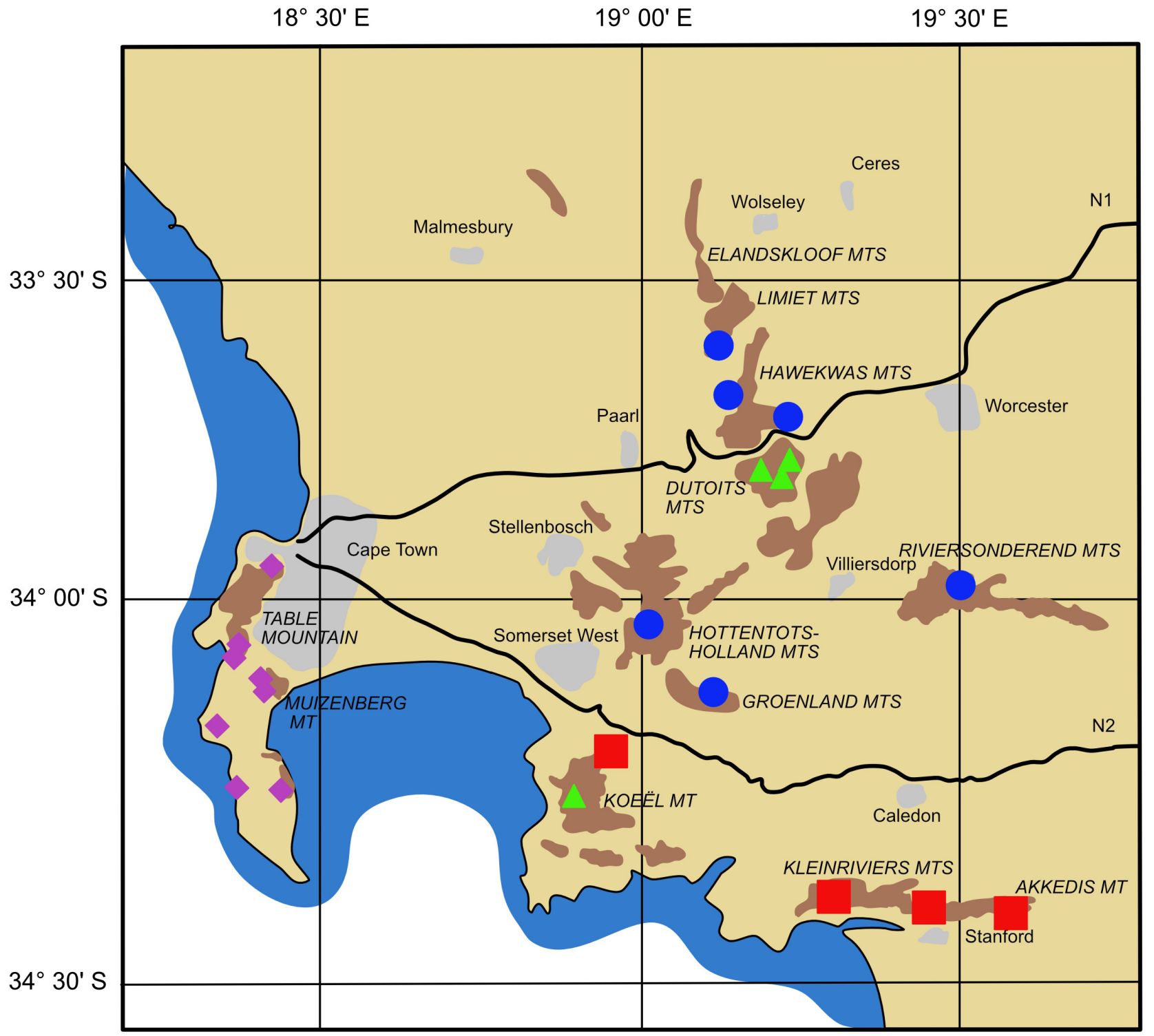

FIGURE 1. Map of the south-western Cape, South Africa, showing the distribution of the material examined. Symbols: Capensibufo deceptus - green triangles; C. magistratus-blue circles; C. rosei-violet diamonds, C. selenophos-red squares. Mountains are indicated in brown, cities and towns in grey. The distribution of $C$. tradouwi falls outside the boundaries of the map.

\section{Materials and methods}

Sampling. Museum specimens were examined from the various mountain ranges where the genus is known to 
occur (Tolley et al. 2010, De Villiers 2004). The material is listed in the species accounts and the localities are mapped in Fig. 1. Additional material from the Hawekwas and DuToits Mountains, listed under the species accounts, has the same sequences as other specimens from those localities (Tolley et al. 2010, Cressey et al. 2014). An additional 16S sequence of C. rosei from Silvermine (Liedtke et al. 2016) has the same sequence as other specimens from that locality. Museum abbreviations: NMB National Museum, Bloemfontein; PEM Bayworld, Port Elizabeth; SAM Iziko Museum, Cape Town.

Morphology. We describe the nuptial pads, parotids, umbraculum, tubercles of the hands and feet, ventral patch, vent margin, snout-urostyle length (SUL), horizontal eye diameter (EYE), horizontal tympanum diameter (TYM), distance between the eye and tympanum (ET), inter-nostril distance (IN), eye to nostril distance (EN), head width (HW), head length from behind the jawbone to the snout tip (HL), snout length (SL), snout to nostril (SNO), interorbital distance measured between the anterior corners of the eyes (EE), distance between the eyes measured across the top of the head (IO), parotid length (PL), maximum parotid width (PW), length of third finger (F3), tibia length (TIB), and foot length from tip of fourth toe to proximal edge of inner metatarsal tubercle (FT). Colour patterns associated with the belly, dorsum, dorsal warts, and limbs were recorded. Measurements were taken with a digital caliper.

Nomenclatural acts. The electronic edition of this article conforms to the requirements of the amended International Code of Zoological Nomenclature, and hence the new names contained herein are available under that Code from the electronic edition of this article. This published work and the nomenclatural acts it contains have been registered in ZooBank, the online registration system for the ICZN. The LSID (Life Science Identifier) for this publication is: urn:Isid:zoobank.org:pub: 5297005A-DF45-43E9-945A-135722DE72EF. The electronic edition of this work was published in a journal with an ISSN, and has been archived and is available from the following digital repository: www.mapress.com/zootaxa/.

Phylogeny. We follow the phylogenies of Tolley et al. (2010) and Cressey et al. (2014), based on 16S and ND2 sequence data. Additional sequences are listed under the species accounts.

\section{Taxonomy}

We treat the distinct clades (Tolley et al. 2010, Cressey et al. 2014) as representing species within the genus Capensibufo. We find that there are at least four species in the C. rosei complex. We describe three new species below.

\section{Capensibufo deceptus sp. nov.}

Deception Peak Mountain Toadlet

(Fig. 2A, B)

Capensibufo rosei (part)

Holotype. A female NMB A8099, collected from a plateau below Deception Peak in the DuToits Mountains $\left(33.78419^{\circ} \mathrm{S}, 19.19886^{\circ} \mathrm{E}, 1686 \mathrm{~m}\right)$, by A. Rebelo, A.A. Turner, D. Rossouw and R. Howat, 19 September 2016.

Paratypes. PEM A10159, a female from below Deception Peak, $1635 \mathrm{~m}$, Dutoits Mountains, South Africa $\left(33.79472^{\circ} \mathrm{S}, 19.21806^{\circ} \mathrm{E}\right)$ collected by M.J. Cunningham and C.L. Henderson, 6 October 2003, and a smaller female NMB A8100 from nearby $\left(33.78397^{\circ} \mathrm{S}, 19.19633^{\circ} \mathrm{E}, 1701 \mathrm{~m}\right)$, collected by A. Rebelo, A.A. Turner, D. Rossouw and R. Howat, 19 September 2016.

Other material. Two large specimens from near the top of Koeël Mountain (Kogelberg) (CNCH 6847-48) are provisionally assigned to this species, on the basis of their large size and the presence of a tympanum. Although $C$. tradouwi also has a tympanum, the nearest confirmed record for this species is on the Langeberg Mountains, 150 $\mathrm{km}$ east. Fresh material for sequencing is required to confirm this assignment.

Sequences. Two 16S sequences FN652323-4 and two ND2 sequences FN650111-2 (Tolley et al. 2010) from Du Toit's Kloof Mountains, vouchers PEM A10159 and MH 0201. The holotype GenBank 16S accession number is KY171944.

Diagnosis. Capensibufo deceptus is larger than the other species in the group. The female holotype SUL 36.3 
$\mathrm{mm}$, and a female PEM A10159, $38 \mathrm{~mm}$. The largest specimens of the other species include C. rosei $28.3 \mathrm{~mm}$ (SAM 43270, Table Mountain), C. magistratus $26 \mathrm{~mm}$ (Jonaskop), and C. selenophos $23.5 \mathrm{~mm}$ (holotype, Maanskynkop). It possesses a visible tympanum, which distinguishes it from C. magistratus, C. rosei, and $C$. selenophos. In preservative, the dorsal spots have no thin white outer margin, which is usually present in $C$. magistratus and C. selenophos. The umbraculum is angular, but rounded in C. rosei, C. selenophos and $C$. tradouwi. Parotids are usually not expanded, in contrast to the wide parotid middle of C. magistratus, $C$. selenophos, and C. tradouwi. The vertebral stripe consists of a thin white line inside a broad pale band, while a vertebral stripe is usually absent in $C$. rosei, and it consists of a diffuse band in C. magistratus. The belly is immaculate to lightly speckled, while there are white spots on a darker background in C. magistratus and $C$. selenophos. Capensibufo tradouwi has a belly that is flecked, the marks running together into thin interrupted lines. The intraspecific uncorrected $\mathrm{p}$ distances for $16 \mathrm{~S}$ are $0-0.2(\mathrm{n}=3)$, and 2.5-3.4 between $C$. deceptus and the other three species previously included in C. rosei, and 2.6-3.8 from C. tradouwi (Table 1).

TABLE 1. Uncorrected $16 \mathrm{~S} p$ distances, as percentages.

\begin{tabular}{lllll}
\hline & C. deceptus $(\mathrm{n}=3)$ & C. magistratus $(\mathrm{n}=14)$ & C. rosei $(\mathrm{n}=13)$ & C. selenophos $(\mathrm{n}=3)$ \\
\hline C. deceptus & $0-0.2$ & & & \\
C. magistratus & $2.5-3.4$ & $0-1.4$ & & \\
C. rosei & $2.8-3.0$ & $2.6-3.8$ & $0-0.4$ & $0.2-0.6$ \\
C. selenophos & $2.6-3.0$ & $3.0-4.0$ & $3.7-4.0$ & $3.8-4.6$ \\
C. tradouwi & $2.6-3.8$ & $3.2-4.5$ & $2.4-4.5$ & \\
\hline
\end{tabular}

Description of holotype. A male, $36.3 \mathrm{~mm}$ SUL, in breeding condition, robust, widest at mid-body; head wide (SUL/HW 2.5), not wider than trunk, wider than long (HW/HL 1.2); snout long (SL/HL 0.39), nearly square in dorsal view, angular in profile, slightly projecting beyond lower jaw, shorter than wide (SL/IO 0.85); canthus rostralis gently rounded; loreal region almost vertical, slightly concave; nostril raised, rimmed, with a small outer flap, directed dorsolaterally; situated closer to eye than to tip of snout, separated from each other by distance less than distance between eye and nostril (IN/EN 0.89); eyes directed anterolaterally, relatively small (EYE/HL 0.3); umbraculum present; eye diameter shorter than snout (EYE/SNT 0.81); interorbital distance less than eye diameter (IO/EYE 0.84), and greater than internarial distance (IO/IN 1.33); tympanum distinct, round, less than eye diameter (TYM/EYE 0.58), situated close to eye (ET/EYE 0.21); choanae small, round, located far anterolaterally at margins of roof of the mouth; no vomer processes; median lingual process of tongue absent. Viewed from below the snout does not protrude beyond the lower jaw.

Lateral and dorsal surfaces of trunk smooth; ventral surfaces of limbs and gular smooth; supratympanic fold absent. Parotid elongated, smooth, not expanded, (PL/PW 2.36), (PL/SUL 0.18); raised, rounded rictal gland behind angle of jaw; inguinal gland rugose, not extending forward beyond thighs; vent opens posteriorly, no large surrounding glandular structures.

Forelimbs moderately robust; hand gracile; tips of fingers rounded, slightly expanded but without discs; relative length of fingers: III $>\mathrm{I}>\mathrm{II}>\mathrm{IV}$ (F3/HW 0.58); subarticular tubercles single, well developed; small supernumerary tubercles present on the palm; thenar tubercle raised; a single rounded metacarpal tubercle present; fingers lightly pigmented, with pigment extending along outer surface of forearm, confluent with dorsal pigment. Nuptial pads cover the upper surfaces of the first two fingers, and the inner surface of the third finger. They consist of small dark raised spots, evenly spaced.

Foot as long as tibia (FT/TIB 0.99); Relative length of toes: $\mathrm{I}<\mathrm{II}<\mathrm{V}<\mathrm{III}<\mathrm{IV}$; subarticular tubercles small, rounded: webbing absent; inner metatarsal tubercle small, prominent; outer metatarsal tubercle flat, rounded.

Colour in life. (Fig. 2A, B) The back is a dark reddish-brown, with a thin pale-grey vertebral stripe. The parotids have a dark orange tinge. The iris is speckled silver. The tympanum is mottled brown. The lateral glandular ridge extending from the parotid is grey, with the posterior third dark orange. The snout is dark brown, extending to the upper lip. A pale area runs from below the eye to the upper lip, continuing as a glandular ridge to the upper arm. The upper surfaces of the limbs are light brown, with darker transverse blotches. The belly is pale grey with darker lateral markings that extend from the back. The inguinal gland is dark red. The throat is white. The soles and palms are black with pale tubercles. 
Colour in preservative. The pattern of the specimen has faded, but some details are apparent. The dorsal spots consist of a dark circle, with no white outer ring. Some specimens have white-tipped warts inside the dark rings. The parotids are orange, and there is a thin white vertebral stripe within a more diffuse pale vertebral band. Ventral markings consist of grey speckles.

Paratype variation. The paratypes are similar in morphology, with the largest female SUL $38 \mathrm{~mm}$. The colour patterns are similar.

Advertisement call. Unknown. This species has a tympanum, and it is expected to produce an advertisement call.

Distribution. The species is so far only known from the DuToits Mountains in South Africa (Fig. 1), from below Deception Peak. Two specimens from Koeël Mountain (Kogelberg) $\pm 980 \mathrm{~m}$ (CNCH 6847-48) have been provisionally assigned to this species. They have snout-urostyle lengths of 31 and $35 \mathrm{~mm}$, much larger than any other species, and both possess a visible tympanum. They were previously called Capensibufo rosei, but the latter does not have a tympanum, nor any hearing organs. This assignment will require fresh material for molecular confirmation.
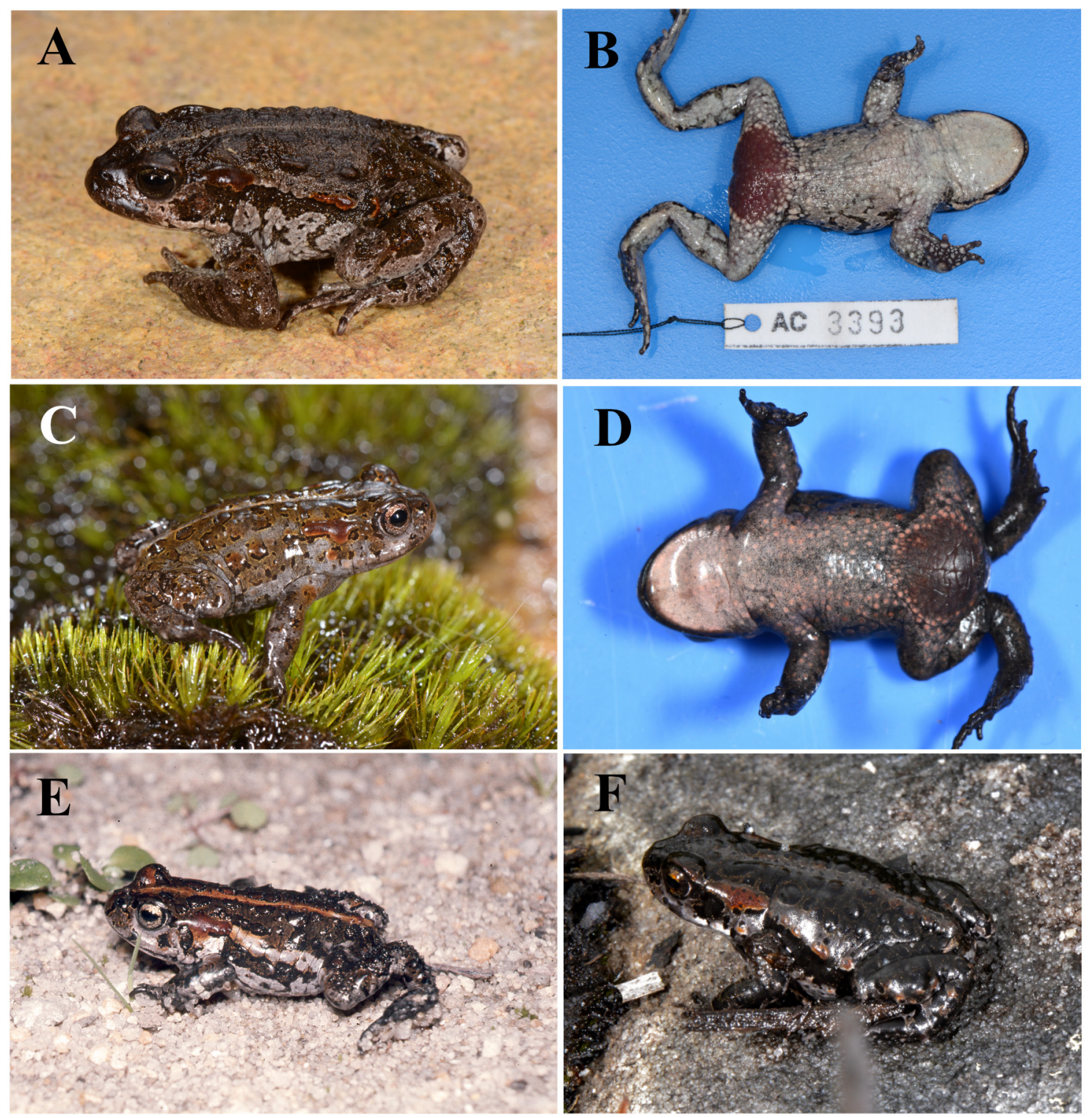

FIGURE 2. Illustrations of the species. A-Capensibufo deceptus (NMB A8099), holotype, Deception Peak. B-Ventral surface of Capensibufo deceptus holotype (NMB A8099). C-Capensibufo magistratus (NMB A8101), holotype, Landdroskop. D-Ventral surface of Capensibufo magistratus (NMB A8102). E-Capensibufo selenophos, no voucher, Maanskyn Nature Reserve. F-Capensibufo rosei, no voucher, Silvermine, Cape Peninsula. 
Etymology. This species is named for the type locality, below Deception Peak, DuToits Mountains, South Africa. The specific epithet is Latin for 'deceive'.

\section{Capensibufo magistratus sp. nov.}

Landdroskop Mountain Toadlet

Capensibufo rosei (part)

Holotype. A male, NMB A8101, collected from Landdroskop in the Hottentot-Holland Mountains, $34.048857^{\circ} \mathrm{S}$, $19.008481^{\circ} \mathrm{E}$, by A. de Villiers and M.E. de Villiers, 25 August 2014.

Paratypes. A female, NMB A8102, collected from Landdroskop in the Hottentot-Holland Mountains, by A.A. Turner, A.L. de Villiers and M.E. de Villiers 21 July 2014, and two males NMB A8103-04 with the same details as the holotype, collected 25 August 2014.

Other material examined. NMB A8105-6, male and female, Hawekwas Mountains; four juveniles NMB A8107-10 and a male NMB A8125 from Landdroskop, Hottentots-Holland Mountains; a female NMB A8111, and three males NMB A8112-4 from Jonaskop, Riviersonderend Mountains; a male PEM A10161 from Groenland Mountains; SAM 50013, Jakkals River, Grabouw. Two females, SAM 19435, Bailey's Peak, Limiet Mountain, Hawekwas Mountains; NMB A8123-24, two specimens from Suurvlakte, Hawekwas Mountains.

GenBank sequences. AF220911, AF463795, Landdroskop (Cunningham \& Cherry 2004), FN652330, FN650126, Landdroskop (Tolley et al. 2010); FN652331-38, FN650127-34, Jonaskop (Tolley et al. 2010); FN652325-27, FN650113, FN650122-3, Hawekwas Mountains (Tolley et al. 2010). KY171942-43, Suurvlakte, Hawekwas Mountains (NMB A18123-24).

Diagnosis. There is no visible tympanum in C. magistratus, which distinguishes it from C. tradouwi and $C$. deceptus. In preservative, the dorsal spots consist of a grey center, with incomplete dark rings, sometimes with thin white outer margins. The umbraculum is angular, separating it from those species with rounded umbracula: $C$. rosei, C. selenophos, and C. tradouwi. The center third of the parotid is usually expanded, while the anterior third is usually wider in $C$. rosei. The parotid of $C$. deceptus is not expanded. There is a broad very diffuse pale vertebral band, sometimes with a thin white mid-dorsal line. The vertebral stripe is usually absent in C. rosei. The ventral markings consist of white spots on a darker background, distinguishing it from those species with immaculate bellies, that are sometimes flecked or marbled: C. deceptus, C. rosei, and C. selenophos. The ratio of parotid length/SUL is usually greater than 0.18 , while it is 0.18 or less in $C$. tradouwi. The intraspecific uncorrected $\mathrm{p}$ distances for $16 \mathrm{~S}$ are $0-1.4(\mathrm{n}=14)$, and $2.5-4.0$ between $C$. magistratus and the other three species previously included in C. rosei and 3.2-4.5 from C. tradouwi (Table 1).

Description of holotype. A male, $19.6 \mathrm{~mm}$ SUL, in breeding condition, robust, widest at mid-body; head wide (SUL/HW 2.6), not wider than trunk, as long as wide (HW/HL 1.1); snout long (SL/HL 0.4), bluntly rounded in dorsal view, angular in profile, slightly projecting beyond lower jaw, shorter than wide (SL/IO 0.73); canthus rostralis rounded; loreal region slightly concave; nostrils with a low rim, situated closer to tip of snout than eye (EN/SNO 1.67), separated from each other by distance about equal to distance between eye and nostril (IN/EN 1.07; eyes directed anterolaterally, relatively small (EYE/HL 0.38); eye diameter less than snout length (EYE/SL 0.77); a small angular umbraculum is present; interorbital distance less than eye diameter (IO/EYE 0.77), and greater than internarial distance (IO/IN 1.25; tympanum absent; choanae small, round, located far anterolaterally at margins of roof of the mouth; no vomer processes; median lingual process of tongue absent. Viewed from below the upper lip protrudes beyond the lower jaw.

Lateral and dorsal surfaces of trunk smooth; ventral surfaces of limbs and gular smooth; parotid elongated, smooth, narrow anteriorly, (PL/PW 3.5), (PL/SUL 0.25); no distinct rictal gland behind angle of jaw; inguinal gland deeply corrugated, extending to level of anterior thighs; vent opens ventrally, small skin folds present but no large surrounding glandular structures.

Fore limbs moderately robust; hand robust; tips of fingers rounded, without discs; relative length of fingers: III $>$ I $>$ II $>$ IV (F3/HW 0.59); distal subarticular tubercle of finger 3 double, all subarticular tubercles well developed; two smaller supernumerary tubercles present on the palm; thenar tubercle flat; a single rounded metacarpal tubercle present. Nuptial pad present as a swollen base of the first finger with a raised glandular pad present on the dorsal surface. 
Foot equal to tibia (FT/TIB 1.01); Relative length of toes: $\mathrm{I}<\mathrm{II}<\mathrm{V}<\mathrm{III}<\mathrm{IV}$; subarticular tubercles small, rounded; webbing absent; inner metatarsal tubercle rounded; outer metatarsal tubercle small, flattened.

Colour in life. The dorsal background is grey, overlain with pale brown. There is a pale grey vertebral stripe. The dorsal warts are darker brown, surrounded by incomplete black rings with a thin yellowish outer border. Numerous small dark brown flecks are distributed across the back. The parotid is reddish brown. The iris has redbrown and silver speckles. The upper lip is grey. The throat is pale with a pinkish tinge. The belly is underlain with grey, with pink spots and black pigment concentrated along the midline. The inguinal gland is very dark red-brown, surrounded by pink spots. The undersides of the limbs are dark brown to black.

Colour in preservative. The dorsal surface has many small brown dots with incomplete black margins, surrounded by a fine white border. There are a few brown-tipped warts within each brown dot. The parotids are brown, and there is a thin pale vertebral stripe. Ventral markings consist of minute white dots that merge to form pale marks laterally and posteriorly. The fingers and toes are dorsally pigmented, confluent with the dorsal pattern.

Paratype variation. The paratype is a $23.7 \mathrm{~mm}$ SUL female. It is similar in body proportions to the holotype, but the umbraculum is rounded, there is a pink tinge to the inguinal patch, the vent opening has fleshy papillae, and the parotid is widest in the middle.

Advertisement call. This species does not make an advertisement call but makes a distress call when disturbed.

Distribution. Landdroskop (on the Hottentots-Holland Mountains), Groenlandberg Mountain, and Limietberg (part of the Hawekwas Mountains), and Jonaskop (on the Riviersonderend Mountains) (Fig. 1).

Etymology. The specific epithet derives from the Latin magister (magistrate), referring to the type locality, Landdroskop. The Afrikaans Landdroskop = Magistrates Peak. It is used as a noun in apposition.

\section{Capensibufo rosei (Hewitt, 1926)}

Material examined. PEM A5132, Muizenberg Mountains (lectotype) (Conradie et al. 2015) (the original description did not specify a holotype); PEM A5134-39, SAM4261 Silvermine River Valley or Muizenberg Mountains; SAM 50008-9 Silvermine Plateau; SAM 17858, SAM 43270, SAM 43812, Table Mountain; SAM 50010-2 Olifantsbos; SAM 50004-7 2.5 km ESE Kommetjie.

GenBank sequences. FN652340-41, FN650136-7, Silvermine (Tolley et al. 2010); HG321460-69, HG321470-82, Silvermine and Cape of Good Hope (Cressey et al. 2014); and an additional 16S sequence KF665475, Steenberg Plateau (Silvermine) (Liedtke et al. 2016).

Diagnosis. There is no tympanum in $C$. rosei, which distinguishes it from $C$. tradouwi and $C$. deceptus. In preservative, the dorsal spots in C. rosei have a brown centre, surrounded by incomplete dark rings. Capensibufo deceptus and C. tradouwi lack a thin outer white ring. Capensibufo magistratus and C. selenophos have incomplete black rings with a thin white outer ring. The umbraculum is rounded, while $C$. deceptus and $C$. magistratus have angular umbracula. The parotid is widest in the anterior third, which distinguishes it from C. magistratus, $C$. selenophos and C. tradouwi. There is usually no vertebral stripe in C. rosei while the other species have thin to broad pale vertebral stripes and/or bands. The belly is immaculate to lightly speckled, while $C$. tradouwi has flecks on the belly that may fuse to form short lines; $C$. magistratus and $C$. selenophos have white spots on a darker background. The ratio of parotid length/SUL is over 0.18, which distinguishes it from $C$. tradouwi, which has a ratio less than 0.18 . The intraspecific uncorrected $\mathrm{p}$ distances for $16 \mathrm{~S}$ are $0-0.4(\mathrm{n}=12)$, and 2.6-4.0 between $C$. rosei $i$ and the other three species previously included in this species, and 2.4-4.5 from C. tradouwi (Table 1). In life the frogs are sometimes very dark, and pattern elements are difficult to discern.

Advertisement call. This species has no advertisement call and makes no distress call when disturbed.

Distribution. This species is limited to the Cape Peninsula, currently known only from both the Silvermine and Cape of Good Hope sections of the Table Mountain National Park. No specimens have been found on Table Mountain itself since 1983 (Cressey et al. 2014). DNA sequences were available from Silvermine and Cape of Good Hope, and museum material was examined from Table Mountain, the Muizenberg Mountains (Silvermine), and the "Cape Peninsula" (Fig. 1).

Remarks. The distribution of this species was previously thought to extend to the mountains west of the Breede River Valley (Grandison 1980). Here we restrict it to the Cape Peninsula, from Table Mountain to the Cape of Good Hope (Fig. 1). 
Capensibufo selenophos sp. nov.

Moonlight Mountain Toadlet

Capensibufo rosei (part)

Holotype. A female, NMB A8115, from Maanskynkop in the Kleinrivier Mountains $\left(34.372889^{\circ} \mathrm{S}, 19.326712^{\circ}\right.$ E), collected by A.L. de Villiers and M.E. de Villiers 27 September 2000.

Paratypes. A male, NMB A8116, from Akkedisberg, Stanford, collected by A.L. de Villiers 1 October 2003, and a female NMB A8117 and juvenile NMB A8118, both from Maanskynkop, with the same details as the holotype.

GenBank sequences. The sequences of the paratypes are FN652328-9, FN652339, FN650124-5 and FN650135 (Tolley et al. 2010).

Other material examined. Two males NMB A8119, SAM 51837, two females NMB A8120, SAM 51825, SAM 51834-8 and a metamorph NMB A8121, all from Maanskynkop Nature Reserve; SAM 50000-4, Stanford; NMB A8122, Mimetes plot, Elgin Forest Reserve, near Rockview Dam, 445 m.

Diagnosis. There is no visible tympanum in C. selenophos, while a tympanum is present in $C$. deceptus and $C$. tradouwi. In preservative, the dorsal spots have incomplete black rings usually with a thin white margin, distinguishing it from $C$. deceptus, which has no white margin. Capensibufo rosei has brown spots with thin black rings, and $C$. tradouwi has thin black rings without a white outer margin. The umbraculum is rounded, distinguishing it from $C$. deceptus and $C$. magistratus, which have angular umbracula. The parotids are flat, broadest in the centre third, while $C$. deceptus and $C$. rosei have parotids that are widest anteriorly. There is a thin white vertebral stripe inside a paler broader vertebral band, distinguishing it from $C$. rosei, which usually has no vertebral stripe. The belly is immaculate or has some pale spots on a darker background, distinguishing it from $C$. deceptus, C. rosei and C. tradouwi which have lightly speckled to marbled markings. The ratio of parotid length/ SUL is greater than 0.18 , distinguishing it from $C$. tradouwi, which has a ratio less than 0.18 . The intraspecific uncorrected $\mathrm{p}$ distances for $16 \mathrm{~S}$ are $0.2-0.6(\mathrm{n}=3)$, and 2.6-4.0 between $C$. selenophos and the other three species previously included in C. rosei and 3.8-4.6 from C. tradouwi (Table 1).

Description of holotype. A male, $23.5 \mathrm{~mm}$ SUL, gracile; head wide (SUL/HW 2.9), as wide as trunk, about as long as wide (HW/HL 1.04); snout moderately long (SL/HL 0.32), bluntly rounded in dorsal view, rounded in profile, slightly projecting beyond lower jaw, shorter than wide (SL/IO 0.73); canthus rostralis gently rounded, indistinct; loreal region convex; nostril delicately rimmed, directed dorsolaterally; situated closer to tip of snout than to eye (EN/SNO 1.78), separated from each other by distance greater than distance between eye and nostril (IN/EN 1.13); eyes directed anterolaterally, relatively small (EYE/HL 0.32); eye diameter equal to snout length (EYE/SL 1.0); interorbital distance less than eye diameter (IO/EYE 0.69), and slightly more than internarial distance (IO/IN 1.11); tympanum not visible; choanae small, round, located far anterolaterally at margins of roof of the mouth; no vomer processes; median lingual process of tongue absent. Viewed from below the upper lip protrudes beyond the lower jaw, but not the snout.

Lateral and dorsal surfaces of trunk smooth with paravertebral rows of nine large warts from behind the eye, and lateral rows of about five warts running from behind the parotid; ventral surfaces of limbs and gular smooth.

Parotid elongated, smooth, expanded anteriorly (PL/PW 3.0), (PL/SUL 0.23); four or five raised, rounded rictal glands behind angle of jaw; inguinal gland rugose, extending forward beyond thighs; vent opens posteriorly, no large surrounding glandular structures.

Fore limbs moderately robust; hand gracile; tips of fingers rounded but without discs; relative length of fingers: III $>$ I $>$ IV $>$ II (F3/HW 0.62); distal subarticular tubercle of finger 3 double, well developed; all other subarticular tubercles single; small supernumerary tubercles present on the palm and base of fingers; thenar tubercle raised; a single rounded metacarpal tubercle present; fingers lightly pigmented ventrally and dorsally, with pigment extending along outer surface of forearm, confluent with dorsal pigment.

Foot as long as tibia (FT/TIB 1.05); relative lengths of toes: $\mathrm{I}<\mathrm{II}<\mathrm{V}<\mathrm{III}<\mathrm{IV}$; subarticular tubercles small, rounded; median subarticular tubercle of the third toe and distal subarticular tubercle of the fourth toe double; webbing absent; inner metatarsal tubercle small, prominent; outer metatarsal tubercle flat, rounded.

Colour in life. This is based on a specimen from Maanskynkop Nature Reserve, that was photographed but not collected (see Fig. 2E). The dorsal background is grey-brown, with an orange vertebral band, enclosing a thin pale 
stripe. The iris is speckled silver. The parotid is reddish-brown. A pale grey lateral band extends from the parotid. The dorsal warts are dark brown, surrounded by a thin black ring. Many have a thin yellowish outer border. The upper lip is grey with small black markings. The upper limbs are grey, mottled with brown and black blotches.

Colour in preservative. The orange has faded to a light tinge, and the lateral band is white. The outer border surrounding the dorsal warts has faded to white.

Paratype variation. The faint white margin around the dorsal spots is absent on the female. The paratypes are otherwise similar in morphology and colour pattern to the holotype. The male paratypes are immature, without nuptial pads.

Advertisement call. This species has no advertisement call.

Distribution. Akkedis Mountain and Maanskyn Nature Reserve, on the Kleinriviers Mountains (Fig. 1), and the lower slopes of the Koeël Mountain near Rockview Dam. The Kleinriviers populations are healthy, found breeding near Stanford in September 2016.

Etymology. The specific epithet derives from the Greek selenóphos (moonlight), in reference to the type locality Maanskyn Nature Reserve (Afrikaans maanskyn= moonlight). It is used as a noun in apposition.

\section{Discussion}

Tympanum presence. Grandison (1980) investigated the cranial anatomy of four specimens not possessing a tympanum that she referred to $C$. rosei, and one with a tympanum that she referred to $C$. tradouwi. It is not possible to determine the localities where these five specimens were collected. Positive morphological evidence for the presence or absence of a columella is therefore not available for the other species reported here.

Twelve specimens from Maclear's Beacon on Table Mountain were used in an osteological study (Martin 1972) which confirmed the absence of a columella, and hence no means for transmission of air-borne sounds to the inner ear. In species that possess a tympanum, it may be obscured, or not visible on one or both sides. The variation in visibility of the tympanum led to some of the early taxonomic confusion in this genus (Poynton 1964), when only two species were recognised. This study recognises two species that possess a tympanum, and three that do not.

Distribution. Specimens of Capensibufo have been reported from Nuweberg Mountains near Viljoen's Pass (De Villiers, 2015) although no material was available to examine. Cressey et al. (2014) provide a list of sites on the Cape Peninsula where specimens of $C$. rose $i$ have been collected. On the peninsula, one locality is known by different names (Kalk Bay Mountain, Muizenberg Mountain, Steenberg Plateau, and Silver Mine (or Silvermine) Nature Reserve.

The distribution of $C$. deceptus seems fragmented and is clearly not very well understood. More detailed collecting is required particularly in mountains that separate this species from C. magistratus and C. selenophos.

Conservation. On September 8, 1965 John Visser and Mills Tandy found hundreds of Capensibufo rosei (sensu stricto) toads beneath decaying vegetation at Maclear's Beacon on Table Mountain, along with thousands of eggs (Tandy \& Keith 1972). This population has not been seen since 1983, one of many populations which are no longer present on the Cape Peninsula (Cressey et al. 2014). In contrast, the population at the Silvermine site has apparently remained consistent since the type collection in 1925 .

Prior to this taxonomic revision, species in the genus Capensibufo were already considered to have a high conservation priority (Measey et al. 2011). Other taxa that have range-restricted montane distributions in the Cape Fold Mountains have been assessed with high extinction risk. For example, over half of the frogs in the genus Arthroleptella are threatened with extinction due to the combined effects of invasive woody vegetation and the resulting increased intensity and frequency of fires (Turner \& Channing 2008). These species have the advantage that their extended calling during winter days makes them possible to detect without particular difficulty, and the distributions of described taxa are well known, despite the rugged terrain. The genus Capensibufo consists of exceedingly cryptic species, many of which do not call, and for those which presumably do, calls are restricted in their timing and are extremely site specific. When inactive, these small toads go largely unnoticed in the environment. Assessing presence or absence is expected to be a major impediment to conservation of this group.

Breeding. All the species of Capensibufo for which breeding sites have been found appear to breed in large aggregations. Masses of eggs are produced by many females. They all use shallow temporary pools with emergent 
sedge-like plants in Mountain Fynbos or Grassy Fynbos in the Fynbos Biome (De Villiers 2004). Not all the species of tadpoles are known. Studies are ongoing, and the tadpoles will be described later once material is available.

The presence of breeding populations is not always consistent. At Landdroskop, for example, breeding took place in the same pool for a number of years, and then moved to a new pool. Over some twenty years of observation, breeding has moved $500 \mathrm{~m}$ or more. There are irregular mountain fires, but some moves take place away from apparently unchanged habitat. This inconsistent use of known breeding pools, with the difficulty of finding the adults, makes it possible that populations could be thought lost, when they have merely moved to a new site. The population of C. magistratus on Jonaskop has not been seen since 2003, although it occurred in a small well-defined site, which was visited in 2011 and 2012.

Future studies. The low altitude specimen from the Koeël Mountains has been provisionally assigned to $C$. selenophos and the high altitude specimens to $C$. deceptus. Molecular data are required to determine if these are correctly assigned, as it is possible that they may represent additional cryptic species.

The diagnoses may require updating when more material becomes available. There is some slight overlap in patterns and proportions, so more than one specimen should be examined where possible, especially when marginal values are found.

\section{Acknowledgements}

We thank the following for providing specimens, photos and logistical support: F. Becker, L. Minter, A.D. Rebelo, J.M. Dehling, M.J. Cunningham, M.E. de Villiers, D. Hamerton (SAM) and W. Conradie (PEM), M. de Kock, J. Buchman, and L. Mossop. R. Howat piloted the helicopter used to reach Deception Peak. Funding was provided by the National Research Foundation of South Africa and the South African National Biodiversity Institute.

\section{References}

Barej, M.F., Rödel, M.-O., Loader, S.P., Menegon, M., Gonwouo, N.L., Penner, J., Cvozdík, V., Günther, R., Bell, R.C., Nagel, P. \& Schmitz, A. (2014) Light shines through the spindrift - Phylogeny of African torrent frogs (Amphibia, Anura, Petropedetidae). Molecular Phylogenetics and Evolution, 71, 261-273. https://doi.org/10.1016/j.ympev.2013.11.001

Channing, A., Measey, G.J., Minter, L. \& Harvey, J. (2011) Understanding and documenting species diversity. In: Measey, G.J. (Ed.), Ensuring a future for South Africa's frogs: a strategy for conservation research. SANBI Biodiversity Series 19. South African National Biodiversity Institute, Pretoria, pp. 12-17.

Channing, A., Hillers, A., Lötters, S., Rödel, M.-O., Schick, S., Conradie, W., Rödder, D., Mercurio, V., Wagner, P., Dehling, J.M., Du Preez, L.H., Kielgast, J. \& Burger, M. (2013) Taxonomy of the super-cryptic Hyperolius nasutus group of long reed frogs of Africa (Anura: Hyperoliidae), with descriptions of six new species. Zootaxa, 3620 (3), 301-350. https://doi.org/10.11646/zootaxa.3620.3.1

Conradie, W. (2014) The king of the dwarves: a new cryptic species of Dainty Frog (Anura: Pyxicephalidae: Cacosternum) from the eastern Great Escarpment of South Africa. Zootaxa, 3785 (3), 438-452. https://doi.org/10.11646/zootaxa.3785.3.6

Cressey, E.R., Measey, G.J. \& Tolley, K.A. (2014) Fading out of view: the enigmatic decline of Rose's mountain toad Capensibufo rosei. Oryx, 49, 521-528. https://doi.org/10.1017/S0030605313001051

Cunningham, M. \& Cherry, M.I. (2004) Molecular systematics of African 20-chromosome toads (Anura: Bufonidae). Molecular Phylogenetics and Evolution, 32, 671-685. https://doi.org/10.1016/j.ympev.2004.03.003

De Villiers, A.L. (2004) Capensibufo rosei (Hewitt, 1926). In: Minter, L.R., Burger, M., Harrison, J.A., Braack, H.H., Bishop, P.J. \& Kloepfer, D. (Eds.), Atlas and Red Data Book of the Frogs of South Africa, Lesotho and Swaziland. SI/MAB Series \#9. Smithsonian Institution, Washington, DC, pp. 87-90.

De Villiers, A.L. (2015) FrogMap. Capensibufo rosei (Hewitt, 1926). Animal Demography Unit. Accessed from: http:// frogmap.adu.org.za/?sp=450 (accessed 21 November 2015)

Frost, D., Grant, T., Faivovich, J., Bain, R., Haas, A., Haddad, C., DeSá, R., Channing, A., Wilkinson, M., Donnellan, S., Raxworthy, C., Campbell, J., Blotto, B., Moler, P., Drewes, R., Nussbaum, R., Lynch, J., Green, D. \& Wheeler, W. (2006) The amphibian tree of life. Bulletin of The American Museum of Natural History, 297, 1-370. https://doi.org/10.1206/0003-0090(2006)297[0001:TATOL]2.0.CO;2 
Grandison, A.G.C. (1980) A new genus of toad (Anura: Bufonidae) from the Republic of South Africa with remarks on its relationships. Bulletin of the British Museum of natural history, Zoology, 39, 293-298.

Hewitt, J. (1926a) Descriptions of new and little-known lizards and batrachians from South Africa. Annals of the South African Museum, 20 (6), 413-431, pls. 35-37.

Hewitt, J. (1926b) Some new or little-known reptiles and batrachians from South Africa. Annals of the South African Museum, 20 (6), 473-490, pls. 44-45.

Liedtke, H.C., Müller, H., Rödel, M.-O., Menegon, M., Gonwouo, L.N., Barej, M.F., Gvoždík, V., Schmitz, A., Channing, A. Nagel, P. \& Loader, S. (2016) No ecological opportunity signal on a continental scale? Diversification and life-history evolution of African true toads (Anura: Bufonidae). Evolution, 70, 1717-1733. https://doi.org/10.1111/evo.12985

Loader, S.P., Ceccarelli, F.S., Wilkinson, M., Menegon, M., Mariaux, J., DeSá, R.O., Howell, K.M. \& Gower, D.J. (2013) Species boundaries and biogeography of East African torrent frogs of the genus Petropedetes (Amphibia: Anura: Petropedetidae) African Journal of Herpetology, 62, 40-48. https://doi.org/10.1080/21564574.2013.781549

Martin, R.F. (1972) Evidence from osteology. In Blair, W.F. (Ed.), Evolution in the genus Bufo. University of Texas Press, Austin, Texas, pp. 37-70.

Measey, G.J., Weldon, C., Morgan, D., Channing, A., Harvey, J. \& Turner, A. (2011) Conservation and ecological studies. In Measey, G.J. (Ed.), Ensuring a future for South Africa's frogs: a strategy for conservation research. SANBI Biodiversity Series 19. South African National Biodiversity Institute, Pretoria, pp.18-28

Poynton, J.C. (1964) The Amphibia of southern Africa: a faunal study. Annals of the Natal Museum, 17, 1-334.

Rose, W. (1926) Some field notes on the batrachia of the Cape Peninsula. Annals of the South African Museum, 20, 433-450, pl. 38.

South African Frog Re-assessment Group (SA-FRoG) \& IUCN SSC Amphibian Specialist Group (2010) Capensibufo rosei. The IUCN Red List of Threatened Species 2010, e.T3776A10070549. https://doi.org/10.2305/IUCN.UK.2010-3.RLTS.T3776A10070549.en

Tandy, M. \& Keith, R. (1972) Bufo of Africa. In: Blair, W.F. (Ed.), Evolution in the genus Bufo. University of Texas Press, Austin, Texas, pp. 119-170.

Tarrant, J., Cilliers, D., Du Preez, L.H. \& Weldon, C. (2013) Spatial assessment of amphibian chytrid fungus (Batrachochytrium dendrobatidis) in South Africa confirms endemic and widespread infection. PLoS ONE, 8 (7), e69591. https://doi.org/10.1371/journal.pone.0069591

Tolley, K.A., De Villiers, A.L., Cherry, M.I. \& Measey, G.J. (2010) Isolation and high genetic diversity in dwarf mountain toads (Capensibufo) from South Africa. Biological Journal of the Linnean Society, 100, 822-834. https://doi.org/10.1111/j.1095-8312.2010.01469.x

Turner, A.A. \& Channing, A. (2008) A new species of Arthroleptella Hewitt, 1926 (Anura: Pyxicephalidae) from the Klein Swartberg Mountain, Caledon, South Africa. African Journal of Herpetology, 57, 1-12. https://doi.org/10.1080/21564574.2008.9635564 